DOI:10.2151/jmsj.2015-048

\title{
Clouds and the Earth's Radiant Energy System (CERES) Data Products for Climate Research
}

\author{
Seiji KATO, Norman G. LOEB \\ Climate Science Branch, NASA Langley Research Center, Virginia, USA \\ David A. RUTAN, and Fred G. ROSE \\ Science System \& Applications Inc., Virginia, USA
}

(Manuscript received 12 February 2015, in final form 11 August 2015)

\begin{abstract}
NASA's Clouds and the Earth's Radiant Energy System (CERES) project integrates CERES, Moderate Resolution Imaging Spectroradiometer (MODIS), and geostationary satellite observations to provide top-of-atmosphere (TOA) irradiances derived from broadband radiance observations by CERES instruments. It also uses snow cover and sea ice extent retrieved from microwave instruments as well as thermodynamic variables from reanalysis. In addition, these variables are used for surface and atmospheric irradiance computations. The CERES project provides TOA, surface, and atmospheric irradiances in various spatial and temporal resolutions. These data sets are for climate research and evaluation of climate models. Long-term observations are required to understand how the Earth system responds to radiative forcing. A simple model is used to estimate the time to detect trends in TOA reflected shortwave and emitted longwave irradiances.
\end{abstract}

Keywords CERES; radiation budget; climate data

\section{Introduction}

The Earth receives energy from the Sun by radiation and emits the energy in space. Non-uniform energy distribution over the globe received from the Sun is the driver of dynamical and hydrological cycles that redistribute the energy. Understanding spatial and temporal distributions of radiation or the irradiance is critical to understand how energy flows within the Earth's system. NASA's Clouds and the Earth's Radiant Energy System (CERES, Wielicki et al. 1996) project provides data of top-of-atmosphere (TOA), surface, and in-atmosphere irradiances. This paper

Corresponding author: Seiji Kato, Mail Stop 420, NASA

Langley Research Center, Hampton, Virginia 23681-2199,

USA

E-mail: seiji.kato@nasa.gov

(C)2015, Meteorological Society of Japan provides descriptions of CERES data products, irradiance uncertainty, and how algorithms used in the CERES process are better than those used in earlier projects such as Earth Radiation Budget Experiment (ERBE, Barkstrom 1984). By providing improvements by the CERES project, this paper describes the advance in estimating radiation budget from observations after CERES instruments started measurements in 2000. It also provides complementary information to a review paper by Ohmura (2014) published in this journal. In addition, a simple model is introduced to understand the climate feedback and time taken to detect TOA irradiance changes.

To those who are interested in the radiation budget estimated by systems before CERES, excellent reviews of the history of Earth radiation budget estimates are given by Hunt et al. (1986) for the pre-satellite era, House et al. (1986) and Hartmann et al. 
(1986) for the satellite era before ERBE, and Kandel and Viollier $(2005,2010)$ after the ERBE era. An overview of the CERES project is given in Wielicki et al. (1996, 1998). The primary objective of the CERES project is to examine the role of cloud and radiation interaction in the Earth's climate system (Wielicki et al. 1996); data products produced by the project have already been used for a variety of climate research.

Currently, two CERES instruments are operated on Terra, two instruments are on Aqua, and one instrument is on Suomi-NPP. CERES instruments on Terra started measurements in March 2000, and those on Aqua started in July 2002. The CERES instrument on Suomi-NPP started measurement in February 2012. All three satellites are on Sun-synchronized orbits. Terra's and Aqua's equator crossing times are 10:30 and 1:30, respectively. CERES instruments can scan along and cross tracked directions (Fixed Azimuth Plane mode). In addition, they can scan along rotating azimuth angles (Rotating Azimuth Plane mode) with unrestricted or restricted azimuth angles. CERES instruments are currently operated in a cross-track scan Fixed Azimuth Plane mode. In this mode, one instrument observes the entire Earth daily. The instruments' footprint size is approximately $20 \mathrm{~km}$. These CERES instruments have been providing continuous global radiation data for more than a decade for the first time in satellite radiation budget observation history.

In the following sections, we describe the accuracy of CERES instruments in Section 2, CERES data products and the uncertainty in TOA and surface irradiances in Section 3, and the variability of TOA and surface radiation budget in Section 4. In Section 5, we discuss the value of long-term radiation budget data in evaluating climate models. A simple analytical model is introduced in Section 6 to help in understanding the climate system that CERES instruments are observing. We estimate the time to detect a trend in the TOA shortwave irradiance using the simple model.

\section{Accuracy and stability of CERES instruments}

CERES instruments have a shortwave channel, a total channel, and a window channel. The accuracy of shortwave CERES instruments is $1 \%$ ( $1 \sigma$ or $\mathrm{k}=1$ ) (Wielicki et al. 1995; Loeb et al. 2009a). The accuracy of the longwave radiance derived from the total channel (i.e., nighttime) is $0.5 \%(\mathrm{k}=1)$ and that derived from total minus shortwave radiances (i.e., daytime) is $1 \%$ (Loeb et al. 2009a). The accuracy is improved by a factor of two from ERBE instruments (Wielicki et al. 1995). The estimated stability of the shortwave irradiance derived from observations by a CERES instrument is $0.3 \mathrm{~W} \mathrm{~m}^{-2}$ per decade (Loeb et al. 2007b). Better accuracy and stability (repeatability and reproducibility, Taylor and Kuyatt 1994) improves the ability of detecting trends; however, natural variability greatly affects the trend detection uncertainty and the time to detect a trend (Loeb et al. 2007b; Wielicki et al. 2013). Even for a perfect instrument, there is uncertainty associated with trend detection because of natural variability or noise (Leroy et al. 2008; Wielicki et al. 2013). An additional requirement is that long-term measurements need to be without a gap for passive instruments because they do not carry an absolute calibration system on board (Loeb et al. 2009b; Wielicki et al. 2013).

\section{Top-of-atmosphere (TOA) and surface irradi- ance data products}

The CERES science team provides instantaneous (Level 2) TOA and surface irradiances by the Single Scanner Footprint (SSF) and Clouds and Radiative Swath (CRS) (Rose et al. 2013) data products, respectively, for every CERES footprint. Gridded (level-3) data products are provided in various temporal scales: 3-hourly (SYNoptic radiative fluxes and clouds, SYN1deg), daily (SYN1deg), and monthly (SSF1deg and SYN1deg). The CRS and SYN data products also include atmospheric irradiances at three pressure levels: $70 \mathrm{hPa}, 200 \mathrm{hPa}$, and $500 \mathrm{hPa}$. A higher level product (Level-3B), the CERES Energy Balanced and Filled (EBAF) product, provides TOA (Loeb et al. 2009a, 2012) and surface (Kato et al. 2013) all-sky and clear-sky irradiances. The EBAF-TOA product uses Argo in-situ ocean heat storage measurements to constrain the TOA net irradiance (Loeb et al. 2009a). The EBAF-surface product uses CALIPSO, CloudSat and AIRS observations to correct bias errors in the cloud, temperature, and humidity profiles used in the surface irradiance computations by matching computed TOA irradiances with CERES-derived TOA irradiances provided by the EBAF-TOA product (Kato et al. 2013).

\subsection{Advancement of CERES algorithms over ERBE algorithms}

Angular distribution models, which provide anisotropic factors, are needed to derive irradiance from scanner radiance measurements. The anisotropic factor depends on the scene viewed, such as surface type, cloud fraction, optical thickness, cloud top 
Table 1. Top-of-atmosphere (TOA) irradiance uncertainty.

\begin{tabular}{lcc}
\hline & Monthly gridded $\left(\mathrm{W} \mathrm{m}^{-2}\right)$ & Global $^{1}\left(\mathrm{~W} \mathrm{~m}^{-2}\right)$ \\
\hline Shortwave & $5.0^{*}$ & 1.0 \\
& $4.0^{+}$ & 1.8 \\
\hline Longwave (day+night) & 2.5 & \\
\hline${ }^{*}$ Terra only, prior to July 2002 & & \\
${ }^{+}$Terra+Aqua, July 2002 onwards & & \\
${ }^{1}$ Annual and monthly &
\end{tabular}

height, and cloud phase, within the field-of-view, in addition to the viewing geometry of the CERES instrument. ERBE relied solely on shortwave and longwave radiances observed by ERBE scanners to identify the scene type (Wielicki and Green 1989). The CERES project collocates MODIS radiances with a $1 \mathrm{~km}$ resolution to identify the scene type (Wielicki et al. 1998). CERES angular distribution models use cloud and surface properties derived from MODIS as well as vertical temperature profiles from reanalysis to convert radiance to irradiance (Loeb et al. 2005). As a result, CERES algorithms can use more precise scene dependent anisotropic factors (Loeb et al. 2003, 2005; Kato and Loeb 2005; Su et al. 2015) compared to the ERBE algorithm that uses only 12 scene types (Green and Avis 1996). Therefore irradiances are improved, especially for clear-sky and regional all-sky irradiances (Loeb et al. 2007a). Other subtle differences between ERBE and CERES algorithms include: 1) CERES adopts a more rigorous unfiltering process and scene dependent unfiltering coefficients (Loeb et al. 2001). The unfiltering process corrects instrument spectral response and converts filtered radiances to unfiltered radiances. As a result of the unfiltering process, the unfiltered shortwave irradiance includes all wavelengths reflected by the Earth. Similarly, the unfiltered longwave irradiance includes all wavelengths emitted by the Earth. 2) The CERES team defines the irradiance reference height as $20 \mathrm{~km}$ (Loeb et al. 2002). Because of the spherical geometry of the Earth, TOA irradiances depend on the altitude where the irradiance is defined. The $20 \mathrm{~km}$ reference altitude is determined by computing the effective radius (radius of the Earth plus the altitude) of the solid disc that intercepts an equivalent amount of solar energy by the Earth. The spectral dependent transmission of the atmosphere needs to be considered to compute the solar energy intercepted by the Earth. Once the irradiance is defined at $20 \mathrm{~km}$, irradiances included in CERES data products are comparable to those computed with a $1 \mathrm{D}$ radiative transfer model. Note that the reference level differs from the height where the radiance is observed. The observation altitude is the satellite altitude so that all absorption and scattering below the altitude is included in the observed radiances. 3) TOA shortwave irradiances include the irradiance reflected through twilight regions where the solar zenith angle is greater than $90^{\circ}$ (Kato and Loeb 2003). As a consequence, the reflected irradiance exceeds the TOA downward solar irradiance over the twilight regions.

\subsection{TOA irradiances and their uncertainty}

The estimated uncertainty in the monthly $1^{\circ} \times 1^{\circ}$ latitude-longitude gridded TOA shortwave irradiance is $4 \mathrm{~W} \mathrm{~m}^{-2}$ when the irradiance is derived using both Terra and Aqua (i.e., observations taken 4 times a day for a given location). Prior to July 2002, when only Terra observations are available, the estimated uncertainty in the TOA gridded monthly mean shortwave irradiance is $5 \mathrm{~W} \mathrm{~m}^{-2}$. The estimated uncertainty in the TOA gridded monthly mean day plus nighttime longwave irradiance is $2.5 \mathrm{~W} \mathrm{~m}^{-2}$ for both Terra only and Terra plus Aqua observations (Doelling et al. 2013). Uncertainties in global monthly and annual mean shortwave and longwave (day+nighttime) irradiances are $1.0 \mathrm{~W} \mathrm{~m}^{-2}$ and $1.8 \mathrm{~W} \mathrm{~m}^{-2}$, respectively (Loeb et al. 2009a). Uncertainties in TOA irradiances are summarized in Table 1.

As mentioned earlier, the highest level data products are the EBAF-TOA and EBAF-surface products. Because the net TOA irradiance nearly matches ocean heating for a global spatial scale and is longer than an annual temporal scale (Loeb et al. 2009a; Loeb et al. 2012), the EBAF-TOA data product uses ocean temperature measurements to adjust TOA net irradiance to $0.58 \mathrm{~W} \mathrm{~m}^{-2}$ (Loeb et al. 2012). To compute the absorbed shortwave irradiance, incoming solar irradiance observed by the Total Irradiance Monitor instrument aboard the Solar Radiation and Climate Experiment is used (Loeb et al. 2012). The uncertainty in the net irradiance at a $90 \%$ confidence level 
Table 2. Summary of uncertainties in the irradiance computed with satellite-derived cloud and aerosol properties in $\mathrm{W} \mathrm{m}^{-2}$ (after Kato et al. 2012).

\begin{tabular}{lcccccc}
\hline & & \multicolumn{5}{c}{ Estimated uncertainty } \\
\cline { 3 - 7 } & & Mean value & Monthly gridded & Monthly zonal & Monthly global & Annual global \\
\hline \multirow{3}{*}{ Downward longwave } & Ocean+land & 345 & 14 & 11 & 7 & 7 \\
& Ocean & 354 & 12 & 10 & 7 & 7 \\
& Land & 329 & 17 & 15 & 8 & 7 \\
\hline \multirow{3}{*}{ Upward longwave } & Ocean+Land & 398 & 15 & 8 & 3 & 3 \\
& Ocean & 402 & 13 & 9 & 5 & 5 \\
& Land & 394 & 19 & 15 & 5 & 4 \\
\hline \multirow{5}{*}{ Downward shortwave } & Ocean+Land & 192 & 10 & 8 & 6 & 4 \\
& Ocean & 190 & 9 & 8 & 5 & 4 \\
& Land & 203 & 12 & 10 & 7 & 5 \\
\hline \multirow{5}{*}{ Upward shortwave } & Ocean+Land & 23 & 11 & 3 & 3 & 3 \\
& Ocean & 12 & 11 & 3 & 3 & 3 \\
& Land & 53 & 12 & 8 & 6 & 6 \\
\hline
\end{tabular}

is $\pm 0.38 \mathrm{~W} \mathrm{~m}^{-2}$. For the net irradiance of $0.58 \mathrm{~W} \mathrm{~m}^{-2}$, $0.47 \mathrm{~W} \mathrm{~m}^{-2}$ is due to heating below a depth of 1800 $\mathrm{m}, 0.07 \mathrm{~W} \mathrm{~m}^{-2}$ is due to heating below $2000 \mathrm{~m}$, and $0.04 \mathrm{~W} \mathrm{~m}^{-2}$ is due to ice warming and melt (Loeb et al. 2009a).

Observing clear-sky radiances by CERES instruments requires cloud-free footprints. If only cloudfree CERES footprints are considered as clear sky, the clear-sky irradiance estimate excludes smaller clear-sky area for which the linear dimension is less than approximately $20 \mathrm{~km}$ at nadir. As a result in an extreme case, no monthly mean clear-sky irradiance is provided over a $1^{\circ} \times 1^{\circ}$ grid where no clear-sky CERES footprints occur over the course of a month. To reduce this sampling problem of TOA clear-sky irradiances, the EBAF product includes clear-sky irradiances derived from MODIS radiances averaged over partly cloudy CERES footprints (Loeb et al. 2009a) in addition to the clear-sky irradiance derived from clear-sky CERES footprints. In addition, the product uses geostationary satellite data to include the diurnal cycle of cloud properties by a similar method described by Doelling et al. (2013).

\subsection{Surface irradiances and their uncertainty}

The CERES science team also provides surface irradiances in various temporal and spatial scales. We use MODIS derived cloud properties (Minnis et al. 2011), including cloud fraction, cloud top height, optical thickness, particles size, and phase, as inputs for a two-stream radiative transfer model. We also use geostationary satellite-derived cloud proper- ties (fraction, optical thickness, and height) to account for the diurnal cycle of clouds (Rutan et al. 2014). Atmospheric thermodynamic state variables used for computations are from NASA Global Modeling and Assimilation Office reanalysis. Because MODIS-derived aerosol optical thickness is only available for clear-sky conditions but the aerosol optical thickness is also needed under cloudy conditions, we use an aerosol transport model (Collins et al. 2001) that assimilates MODIS-derived optical thickness. The aerosol transport model also provides aerosol types, which determine the single scattering albedo and asymmetry parameter used in the radiative transfer model.

Ocean surface albedo is based on measurements at the Chesapeake lighthouse (Jin et al. 2004). Surface albedos over land are constrained by clear-sky CERES observations (Rutan et al. 2009). The emissivity of land and ocean surfaces is from Wilber et al. (1999). The uncertainty of surface irradiances is given in Table 2.

The surface radiation budget and its changes as a response to radiative forcing are important for several reasons. First, climate models indicate that the changes in precipitation as responses to radiative forcing are driven by surface radiation budget changes (Stephens and Ellis 2008). Second, for a global annual scale, the net surface irradiance matches the sum of surface latent and sensible heat fluxes and ocean heating. Because the latent and sensible heat fluxes are difficult to observe globally, the net surface irradiance might be used to constrain these fluxes. A recent 
satellite estimate of surface fluxes is given in Stephens et al. (2012). Although the global annual mean net surface irradiance, latent and sensible heat, and ocean heating can be forced to balance when all components are altered up to the corresponding 1-sigma uncertainty (L'Ecuyer et al. 2014), a significant discrepancy of approximately $15 \mathrm{~W} \mathrm{~m}^{-2}$ exists when all satellite estimates are combined (e.g., Kato et al. 2011). Because the sensible heat is small $\left(23 \mathrm{~W} \mathrm{~m}^{-2}\right.$, Stephens et al. 2012), the discrepancy is considered to be caused by either the net surface irradiance or the latent heat flux, which must balance with precipitation, or both. When the CERES-EBAF-surface product and Global Precipitation Climatology Project (GPCP, Huffman et al. 1997) product are combined with the surface sensible heat flux of $17 \mathrm{~W} \mathrm{~m}^{-2}$ (Trenberth et al. 2009), there is a discrepancy of $16 \mathrm{~W} \mathrm{~m}^{-2}$ where the net surface irradiance is higher.

\subsection{Evaluation of surface irradiance}

We evaluate computed surface irradiances with observed irradiances at many surface sites. Currently, we use 37 land sites and 49 ocean buoys. Land sites that are used in the evaluation are among the Baseline Surface Radiation Network (BSRN, Ohmura et al. 1998) operated by NOAA's Global Monitoring Division (GMD, Augustine et al. 2000), the US Dept. of Energy's Atmospheric Radiation Measurement (Ackerman and Stokes 2003) program, and NOAA's GMD whose data are made available through the NOAA/GMD Solar and Thermal Radiation group. In addition, SURFRAD data are made available through NOAA's Air Resources Laboratory/Surface Radiation Research Branch (Rutan et al. 2014). Buoy observations are available from two sources. The Upper Ocean Processes group at Woods Hole Oceanographic Institute has maintained the Stratus, North Tropical Atlantic Site, and Hawaii Ocean Time Series buoys. The Project Office of NOAA's Pacific Marine Environmental Labs provided the Tropical Atmosphere Ocean/Triangle Trans-Ocean Buoy Network (TAO/TRITON) (McPhaden 2002), the Prediction and Research Moored Array in the Tropical Atlantic (PIRATA) (Servain et al. 1998), and the Research Moored Array for African-Asian-Australian Monsoon Analysis and Prediction (RAMA) (McPhaden et al. 2009). Detailed descriptions about these validation sites are given in Rutan et al. (2014).

When computed monthly $1^{\circ} \times 1^{\circ}$ gridded mean downward irradiances from EBAF-surface Edition 2.8 are compared with 10 years of observed irradiances, the bias averaged over all land and ocean sites are $-0.9 \mathrm{~W} \mathrm{~m}^{-2}$ and $4.0 \mathrm{~W} \mathrm{~m}^{-2}$ for surface downward shortwave irradiance and $-1.2 \mathrm{~W} \mathrm{~m}^{-2}$ and $-1.6 \mathrm{~W} \mathrm{~m}^{-2}$ for surface downward longwave irradiance, respectively (Fig. 1). These are well within the estimated uncertainty of the daily or annual mean of surface downward shortwave irradiances of 5 to $6 \mathrm{~W} \mathrm{~m}^{-2}$ and downward longwave irradiance of $5 \mathrm{~W} \mathrm{~m}^{-2}$ (Ohmura et al. 1998; Colbo and Weller 2009).

In addition to the monthly mean irradiance, Fig. 2 shows that the computed and observed deseasonalized anomalies averaged at all sites agree well when the time series of irradiance deseasonalized anomalies are compared using data from March 2000 through December 2007 (Rutan et al. 2014). Monthly deseasonalized anomalies are computed by subtracting the climatological monthly mean computed for each canonical month using the entire period from the corresponding month. For computed irradiances from EBAF-surface Ed. 2.8, $1^{\circ} \times 1^{\circ}$ grids that contain surface sites are averaged. The correlation coefficient of the deseasonalized anomaly time series is 0.95 for both the downward shortwave and the downward longwave irradiances.

\section{Variability of TOA and surface irradiances}

Researchers recognized that clouds largely influence the albedo of the Earth since the beginning of global albedo estimations. Abbot and Fowle (1908a, b) included two types (high and low) of clouds in estimating the global albedo. Regional TOA albedos and cloud radiative effects were estimated by Stephens and Greenwald (1991a, b) from Nimbus-7 Earth radiation budget instruments. Clouds increase the TOA albedo while decreasing outgoing longwave irradiance. One of the ERBE objectives was to investigate which effect is larger and to understand whether clouds warm or cool the planet. A study by Ramanathan et al. (1989) that used April 1985 ERBE data and by Harrison et al. (1990) that used ERBE data from April 1985 through January 1986 concluded that clouds cool the planet, i.e., the cloud radiative effect on TOA albedo is larger than the effect on TOA longwave irradiance.

Because the cloud radiative effect is defined as the irradiance observed under an all-sky condition minus the irradiance observed under a clear-sly condition, an observationally derived cloud radiative effect depends on both cloud properties and clear-sky irradiances (Cess et al. 1987, 1992; Soden et al. 2008; Stevens and Schwartz 2012). Observed mean clear-sky irradiance is weighted by clear-fraction, unlike clear-sky TOA irradiance computed by removing clouds, which 

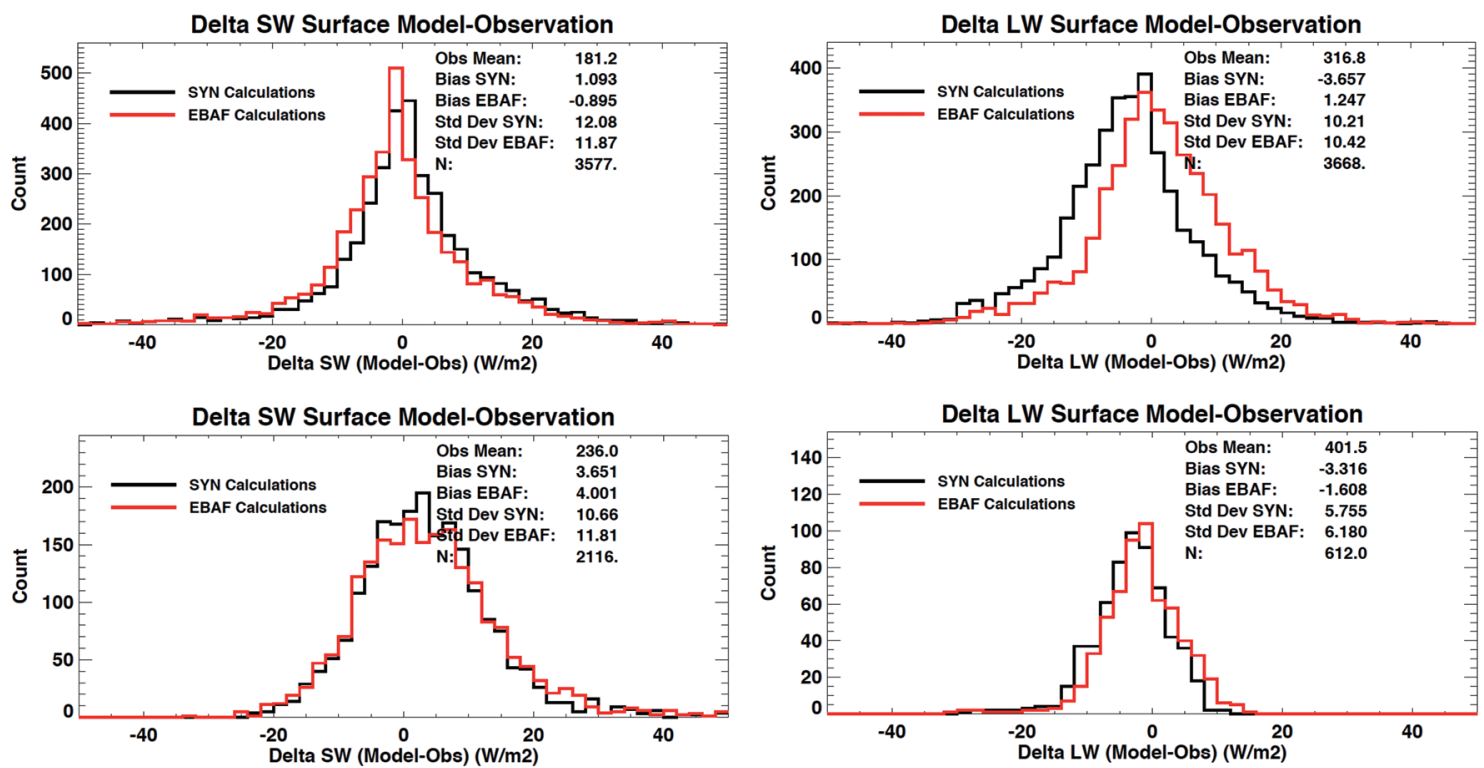

Fig. 1. Occurrence of computed minus observed monthly mean (top left) downward shortwave irradiance and (top right) downward longwave irradiance over 37 land sites. The bottom two plots are the same as top plots, but modeled and observed irradiance over 49 ocean buoys are used. The location of land sites and buoys is given in Rutan et al. (2014). 10 years of data from March 2000 through February 2010 are used. Black and red lines are for SYN and EBAF, respectively. EBAF irradiances apply adjustments to cloud, atmospheric, and surface properties based on CERES-derived TOA shortwave and longwave irradiances. No adjustments are applied to SYN irradiances.
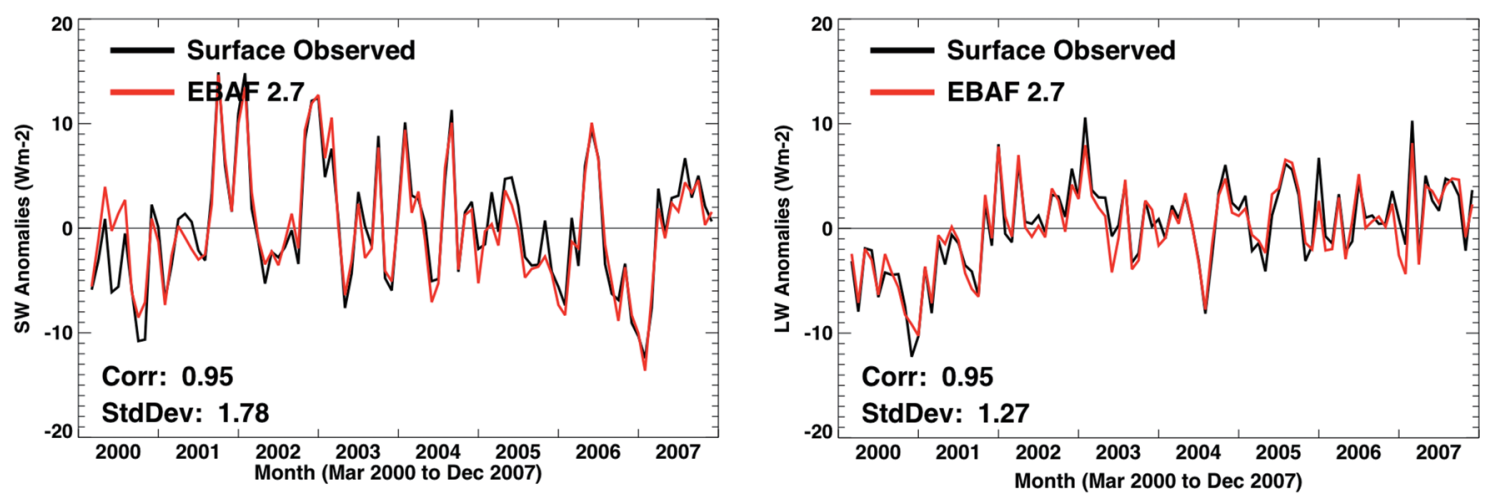

Fig. 2. Time series of surface downward (left) shortwave and (right) longwave monthly deseasonalized anomalies. Anomalies were computed over 37 land sites and 49 buoys (after Rutan et al. 2014).

samples uniformly. Raschke at al. (2005) and Zhang et al. $(1995,2004)$ use cloud properties from ISCCP (Rossow and Schiffer 1991, 1999) and compute TOA irradiances. In their approach, the cloud radiative effect can be computed by removing clouds in the same way in which the cloud radiative effect is computed in climate models. CERES also provides computed clear-sky irradiances by removing clouds in SYN1deg and CRS. The difference due to the regional shortwave cloud radiative effects by observation and cloud removal is not as large as the difference due to longwave cloud radiative effects (Allan and Ringer 2003; Sohn and Bennarts 2008; Sohn et al. 2010; Kato et al. 2013), but large shortwave cloud radiative 
effect differences occur at high-latitudes (Kato et al. 2013). The difference is caused by a clear-sky irradiance difference due to an anti-correlation between sea ice and clouds. Observed clear sky during the sea ice melting season tends to be high because clear sky tends to occur over sea ice.

\subsection{Albedo variability}

Because of the short lifetime of ERBE scanner instruments and because ERBS nonscanners cover only over the tropics, only Nimbus-6 and -7 ERB instruments provided observations to analyze the interannual variability of the global TOA albedo (Smith and Smith 1987; Randel and Vonder Haar, 1990; Smith et al. 1990; Ringer 1997) before observations by CERES instruments on Terra and Aqua. Several studies, however, address the variability of TOA irradiance before CERES. Ringer (1997) used Nimbus-7 data to show that tropical albedo variability is largely caused by ENSO. Wielicki et al. (2002) and Wong et al. (2006) analyzed interannual variability of TOA albedo and emitted longwave irradiance between $20^{\circ} \mathrm{S}$ to $20^{\circ} \mathrm{N}$ using an ERBE nonscanner on the ERBS satellite. Interannual variability of the TOA albedo from $60^{\circ} \mathrm{N}$ to $60^{\circ} \mathrm{S}$ derived from Nimbus-7 ERB instruments and its sensitivity to the cloud amount is investigated by Ringer and Shine (1997).

Regional cloud amounts over the tropics depend on ENSO (e.g., Klein et al. 1999), and TOA albedo variability over the tropics is highly correlated with cloud amount (Loeb et al. 2007c; Kato 2009). The albedo is also influenced by cloud vertical structure (Cess et al. 2001; Allan et al. 2002; Loeb et al. 2012).

\subsection{Diurnal cycle of albedo}

Diurnal variability of albedo over the southern Pacific ocean where the diurnal cycle of low-level cloud fraction exists was investigated by Minnis and Harrison (1984). While the cloud amount of marine stratocumulus reaches a maximum in the morning (e.g., Rozendaal et al. 1995), the low-level cloud amount over land reaches a maximum in early afternoon (Cairns 1995). Mid- and high-clouds reach maxima in nighttime and early morning, respectively (Cairns 1995). The effect of diurnal cycle of cloud properties on albedo was investigated by Hartmann et al. (1991) and Haeffelin et al. (1999). Potter et al. (1988) and Young et al. (1998) discuss the method to include the diurnal cycle of albedo in radiation budget estimates from satellite observations. Zhang and Rossow (1995) and Rossow and Zhang (1995) use ISCCP-derived clouds and compute irradiance at 3-hourly intervals to include the diurnal cycle in radiation budget estimation. The result of Doelling et al. (2013) shows that the regional monthly mean reflected TOA shortwave irradiance is influenced by the diurnal cycle of marine stratus and land convective clouds. The global annual mean reflected shortwave irradiance increases by $1 \%$ when their diurnal cycle is considered in the estimate (Doelling et al. 2013). However, the effect of the diurnal cycle on the albedo trend and variability over the tropics appears to be negligible (Taylor and Loeb 2013).

\section{Using CERES data for climate model validation}

Mean states from CERES data are used for climate model validations in many studies (e.g., Su et al. 2010; Cheng and $\mathrm{Xu}, 2011$; Cole et al. 2011; Dessler 2013; Xu and Chen 2013a, b; Tsushima and Manabe 2013; Painemal et al. 2014). Evaluations by mean states do not necessarily require long-term observations. Long-term radiation budget observations are needed, for example, in evaluating low-level cloud feedback. Prediction of low-level cloud feedback causes a large uncertainty in predicting climate change. Although recent studies indicate that the cloud feedback is probably a positive feedback (Soden et al. 2008), the cloud feedback parameter estimated from climate models shows a wide spread (Flato et al. 2013; Sherwood et al. 2014). Qu et al. (2014) argue that low-level cloud feedback is primarily controlled by two variable changes: the strength of the inversion and the sea surface temperature. Most climate models show that the low-level cloud cover increases with inversion strength while it decreases with sea surface temperature $(\mathrm{Qu}$ et al. 2014). The ensemble-mean of the estimated inversion strength and sea surface temperature changes from CMIP3 and CMIP5 models are both positive. These suggest that the actual cloud feedback depends on the magnitude of the inversion strength, sea surface temperature change, and cloud fraction response to the feedback. Most models predict a larger sea surface temperature change than the inversion strength change. Qu et al. (2014) argue that a larger sea surface temperature is physically plausible because surface and $700 \mathrm{hPa}$ air temperature changes are coupled. Their study, however, also reveals that the low-level cloud cover change predicted by climate models depends on parameterization $(\mathrm{Qu}$ et al. 2014). Even though cloud parameterization can be evaluated with short term data by comparing, for example, low-level cloud fraction change with sea 

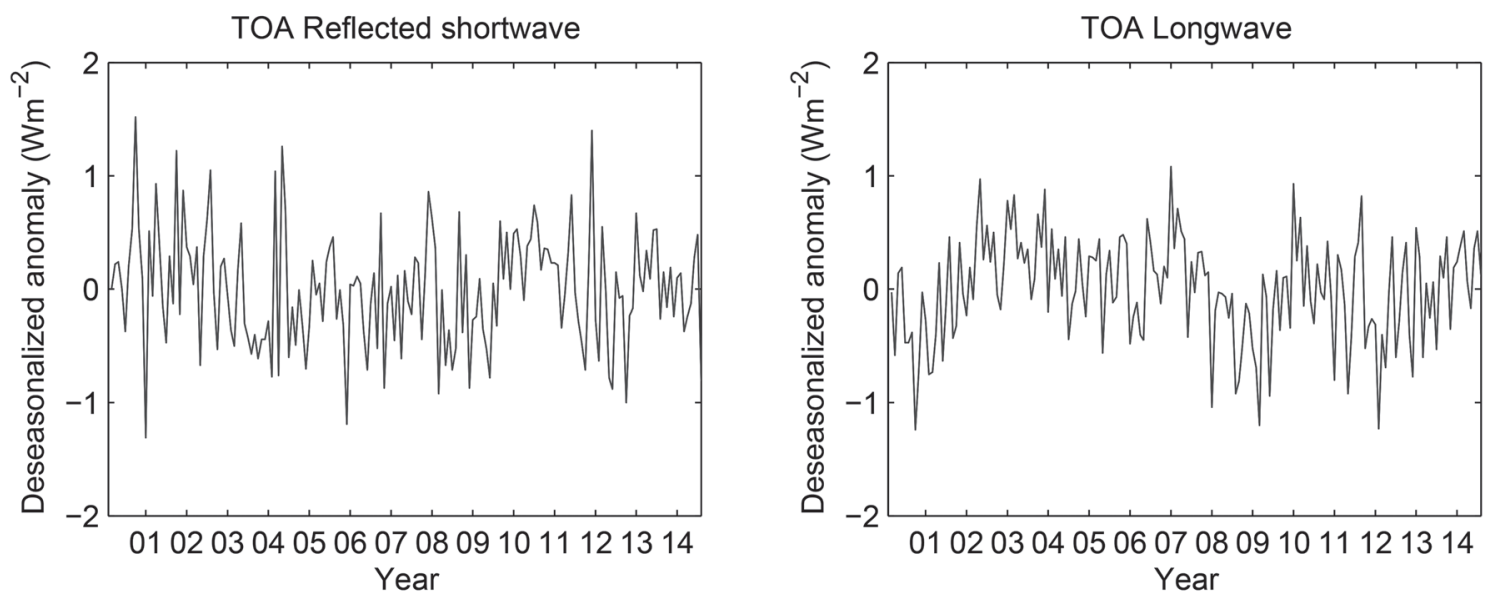

Fig. 3. Time series of deseasonalized top-of-atmosphere (TOA) reflected shortwave (left) and TOA emitted longwave (right) irradiances derived from CERES observations.

surface temperature or inversion strength change, the cloud feedback is determined by the subtle balance among cloud responses to stability and sea surface temperature, and their changes. In addition, other meteorological and cloud property changes might alter the cloud response and stability and sea surface temperature change. These suggest that long-term observations are indispensable in evaluating feedbacks in climate models.

We have nearly 15 years of CERES data (Fig. 3). As demonstrated in the next section, fifteen years are too short to determine cloud feedback because of natural variability of TOA irradiances and because the signal is too small (Wielicki et al. 2013). Wielicki et al. (2013) estimate that more than 40 years are needed to observe cloud feedback at a $95 \%$ confidence level with CERES instruments if the cloud radiative effect trend is $5 \%$ per decade, which is within a spread of CMIP3 model predictions.

However, it does not mean that efforts to use satellite data to estimate cloud feedback are absent. Dessler $(2010,2013)$ uses CERES-derived TOA cloud radiative effect with global mean surface temperature to derive the cloud feedback parameter, although, he recognizes that the feedback parameter derived from a longer record is different from that derived from a shorter time record. In addition, CERES and ISCCP data have been used to estimate TOA irradiance changes responding to sea surface temperature and inversion stability (Eitzen et al. 2011; Qu et al. 2014). In a shorter time scale, dominant causes affecting TOA irradiances are the atmospheric response to ENSO and synoptic systems instead of the response to the radiative forcing due to increasing $\mathrm{CO}_{2}$. The TOA irradiance change due to atmospheric response to ENSO or synoptic system is, however, noise to the climate change signal. Then, do we have to wait for multi-decades or even a century of TOA irradiance measurements to evaluate feedbacks in climate models? We argue that the atmospheric response to ENSO or TOA irradiance variability over a shorter time scale provide a useful evaluation for climate models. Because the system generating noise is the same system that responds to the radiative forcing, the variability of TOA shortwave and longwave irradiances contains the information of the response to the radiative forcing; however, extracting the information is difficult.

\section{Simple analytical model}

To demonstrate how the climate change signal appears in the TOA reflected shortwave and emitted longwave irradiances, we constructed a simple model. We also found that such a heuristic 1D-ocean and -atmosphere model is useful to understand a radiatively forced climate system and the time to detect climate change signals. Note that Hansen et al. (1985) indicate that simple models with an aqua planet tend to underestimate the feedback parameter because ocean heating of an aqua planet is smaller than that of a planet with lands and oceans. In this work, feedback parameters are taken from Table 9.5 of IPCC report Chapter 9 (Flato et al. 2013) and the model is used to understand the climate system instead of estimating feedback parameters.

The system consists of an ocean effective layer of 
depth $l$ in which temperature change $\Delta T$ drives the feedback of the system. The feedback parameter is $\lambda-\beta$, where $\beta$ is the Planck feedback parameter and $\lambda$ is the sum of all other feedback parameters. We further assume that radiative forcing to the system is a combination of linearly increasing forcing with time with the rate of $f$ and a constant forcing $F_{a}$. Radiative forcing increasing with time is due to increasing concentration of carbon dioxide and constant forcing is, for example, due to aerosols. The ocean effective layer transports energy to a deeper layer with a rate $h$ proportional to time (Gregory 2000). The rate of the temperature change of the ocean effective layer is then

$$
c_{p} \rho l \frac{d \Delta T}{d t}=(f-h) t+(\lambda-\beta) \Delta T+F_{a} .
$$

To solve Eq. (1), we take a derivative with respect to time

$$
c_{p} \rho l \frac{d^{2} \Delta T}{d t^{2}}=(f-h)+(\lambda-\beta) \frac{d \Delta T}{d t} .
$$

The initial condition is $\Delta T=0$ when $t=0$. The solution satisfies both equations and the initial condition is

$$
\begin{aligned}
& \Delta T=\left[\frac{F_{a}}{\lambda-\beta}+\frac{c_{p} l \rho(f-h)}{(\lambda-\beta)^{2}}\right] \\
& \left(\frac{\lambda-\beta}{e^{c_{p} \rho l}} t-\frac{(f-h) t}{F_{a}+\frac{c_{p} l \rho(f-h)}{\lambda-\beta}}-1\right) .
\end{aligned}
$$

For $\beta>\lambda$ and $t \gg 1$,

$$
\Delta T \approx\left[\frac{F_{a}}{\lambda-\beta}+\frac{c_{p} \rho l(f-h)}{(\lambda-\beta)^{2}}\right] t\left(-\frac{F_{a}}{f-h}+\frac{c_{p} \rho l}{\beta-\lambda}\right)^{-1} .
$$

Terms in the square bracket on the right side of Eq. (4) are temperature increases at the time equal to time constants. The first term is the temperature increase needed to offset the aerosol forcing by feedback processes. The second term can be separated into a product of two terms:

$$
\frac{c_{p} \rho l(f-h)}{(\lambda-\beta)^{2}}=\frac{c_{p} \rho l}{\beta-\lambda} \frac{f-h}{\beta-\lambda} .
$$

The first term on the right side is a time constant and the second term is the rate of the temperature increase. Terms in the parenthesis on the right side of Eq. (4) are also time constants. The first constant $\frac{F_{a}}{f-h}$ is the time when the sum of $\mathrm{CO}_{2}$ forcing and vertical ocean heat transport is equal to the aerosol radiative effect. The second time constant $\frac{c_{p} \rho l}{\beta-\lambda}$ is the time required to change the ocean effective layer temperature by 1 $\mathrm{K}$ by feedback. The second time constant is equivalent to the fast relaxation time scale given by Held et al. (2010) with no vertical energy transport in the ocean.

The time constant in the parentheses of Eq. (4) that divides time depends on $F_{a}$; when $F_{a}<0$, the time constant is larger by $-\frac{F_{a}}{f-h}$, so that it takes longer to reach $\Delta T$ than the time when $F_{a}=0$. When the temperature change by $F_{a}$ is small compared to the second term, the steady state solution is

$$
\Delta T \approx \frac{f-h}{\beta-\lambda} t,
$$

and the transient climate response is $1 /(\beta-\lambda)$ multiplied by the TOA radiative forcing by doubling $\mathrm{CO}_{2}$.

We can rewrite Eq. (1) to express the net TOA irradiance. Because the global mean net TOA irradiance agrees with the ocean heating rate for a time scale longer than annual (Loeb et al. 2009a),

$$
c_{p} \rho l \frac{d \Delta T}{d t}+h t=f t+(\lambda-\beta) \Delta T+F_{a}=F_{s w}-F_{l w},
$$

where $F_{s w}$ is the absorbed shortwave irradiance by the system (i.e., the net shortwave irradiance at TOA), and $F_{l w}$ is the upward longwave irradiance at TOA.

\subsection{TOA Shortwave and longwave irradiance trend}

When radiative forcing and vertical energy transport within the ocean are not time dependent, the TOA net irradiance trend decays with time with the time constant of $\left(\frac{\lambda-\beta}{c_{p} \rho l}\right)^{-1}$. When they are time dependent, as expressed in Eq. (7), taking the derivative of Eq. (7) with respect to time, we can compute the trend of the net TOA irradiance. As the system approaches a steady state, $\Delta T$ linearly increases, and the trend of TOA net irradiance decreases when approaching $f+(\lambda-\beta) \frac{d \Delta T}{d t}$.

When feedback processes primarily affecting TOA shortwave $\lambda_{s w}$ and longwave $\lambda_{l w}$ irradiances are separated, the net TOA shortwave irradiance change is the rate of temperature change multiplied by the shortwave feedback parameter: 

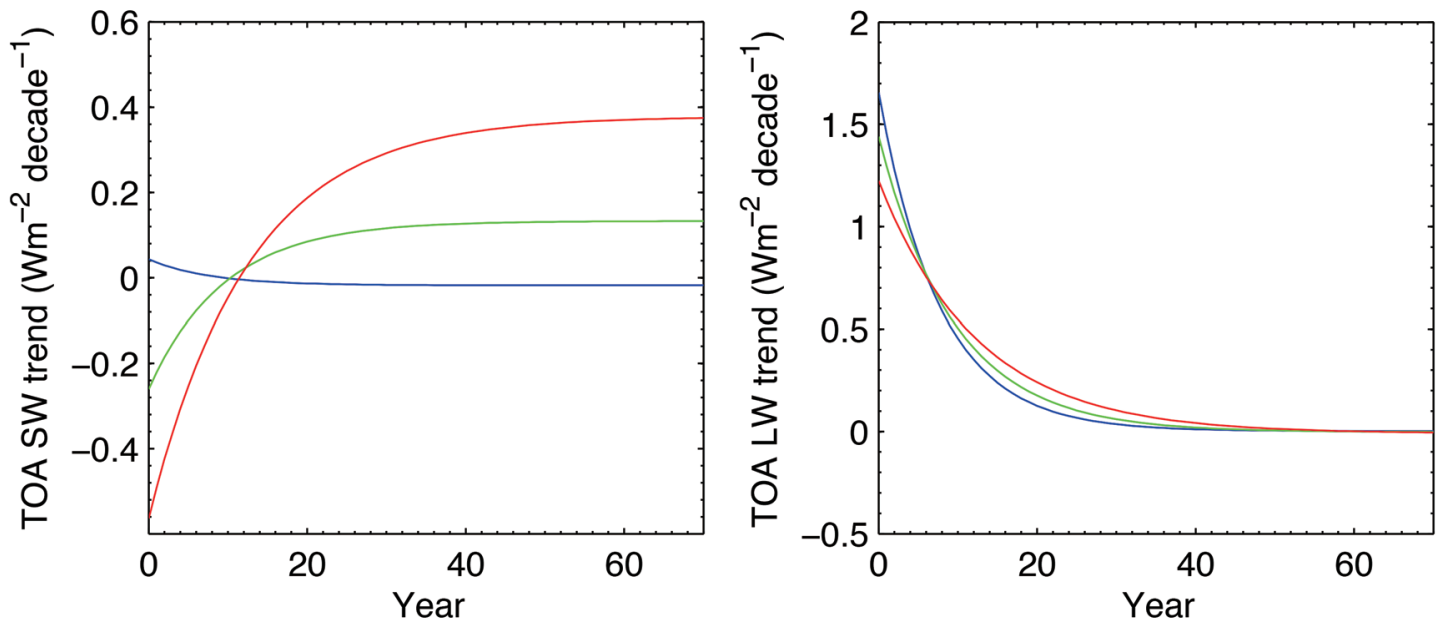

Fig. 4. Trends of (left) net and (right) computed shortwave irradiance and emitted longwave irradiance by Eqs. (8) and (9), respectively. Blue, green, and red lines are, respectively, $\lambda_{\mathrm{sw}}=-0.1,0.6$, and $1.3 \mathrm{~W} \mathrm{~m}^{-2} \mathrm{~K}^{-1}$ for shortwave and $\lambda_{\mathrm{lw}}=0.5,1.0$, and $1.5 \mathrm{~W} \mathrm{~m}^{-2} \mathrm{~K}^{-1}$ for longwave.

$$
\begin{aligned}
c_{p} \rho l & \frac{d^{2} \Delta T}{d t^{2}}+h=\lambda_{s w} \frac{d \Delta T}{d t} \\
& =\frac{\lambda_{s w}}{c_{p} \rho l}\left[(f-h) t+(\lambda-\beta) \Delta T+F_{a}\right] .
\end{aligned}
$$

Here, we assume that the radiative forcing does not directly affect the net TOA shortwave irradiance. Similarly, the TOA emitted longwave irradiance change is the sum of the rate of temperature change multiplied by $\left(\lambda_{l w}-\beta\right)$ and the rate of forcing change:

$$
\begin{aligned}
& c_{p} \rho l \frac{d^{2} \Delta T}{d t^{2}}+h=f+\left(\lambda_{l w}-\beta\right) \frac{d \Delta T}{d t} \\
& =f+\frac{\left(\lambda_{l w}-\beta\right)}{c_{p} \rho l}\left[(f-h) t+(\lambda-\beta) \Delta T+F_{a}\right] .
\end{aligned}
$$

Figure 4 shows the trend of the net TOA shortwave irradiance and emitted longwave irradiance. The rate of changing radiative forcing $f=0.049 \mathrm{~W} \mathrm{~m}^{-2} \mathrm{yr}^{-1}$ ( $3.4 \mathrm{~W} \mathrm{~m}^{-2}$ divided by 70 years), $h=0.002 \mathrm{~W} \mathrm{~m}^{-2}$ $\mathrm{yr}^{-1}\left(0.14 \mathrm{~W} \mathrm{~m}^{-2}\right.$ divided by 70 years), $F a=-1.17 \mathrm{~W}$ $\mathrm{m}^{-2}$, and the depth of the ocean effective layer $l=150$ $\mathrm{m}$ are used. The net shortwave trend changes with time and approaches a constant value corresponding to $\lambda_{s w} \frac{d \Delta T}{d t}$ with a time constant of $\frac{c_{p} \rho l}{\lambda_{s w}}$. Similarly, the longwave trend changes with time and approaches a constant value corresponding to $f+\left(\lambda_{l w}-\beta\right) \frac{d \Delta T}{d t}$ with a time constant of $\frac{c_{p} \rho l}{\lambda_{l w}-\beta}$. The trend of the net
TOA irradiance is $f+(\lambda-\beta) \frac{d \Delta T}{d t}$, which is equal to the trend of ocean heating $c_{p} \rho l \frac{d^{2} \Delta T}{d t^{2}}+h$ by Eq. (7). In the following section, a rough estimate of the time to detect the trend of TOA reflected shortwave irradiance is provided.

\subsection{Time to detect a trend}

The net TOA shortwave and longwave irradiance trends estimated in the previous section can be used to estimate the time to detect trends by a perfect instrument. The effect of instrument calibration uncertainty and sampling uncertainty is discussed in Wielicki et al. (2013). We use the TOA shortwave irradiance trend computed by the simple model as an example to estimate the time taken to detect a trend. When the trend of TOA downward shortwave irradiance is negligible, the net shortwave irradiance trend is equal to the reflected shortwave trend, and it is equivalent to the shortwave feedback parameter that is due to low-level cloud and albedo feedbacks multiplied by the rate of surface temperature change (Eq. 8). We use a formula given by Weatherhead et al. (1998) to estimate the time to detect the trend of reflected shortwave irradiance because the time series of deseasonalized reflected shortwave irradiances follows a firstorder autoregressive model (Phojanamongkolkij et al. 2014). The number of years $n *$ to detect a trend from time series of monthly deseasonalized anomalies is 
Table 3. Number of years to detect TOA reflected shortwave irradiance trend at the $95 \%$ confidence level with a probability of $90 \%$.

\begin{tabular}{lccc}
\hline Shortwave Feedback parameter $\left(\mathrm{W} \mathrm{m}^{-2} \mathrm{~K}^{-1}\right)$ & -0.1 & 0.6 & 1.3 \\
Steady state TOA SW trend $\left(\mathrm{W} \mathrm{m}^{-2} \mathrm{decade}^{-1}\right)$ & -0.018 & 0.133 & 0.375 \\
Number of years to detect trend $(\mathrm{yr})$ & 697 & 94 & 33 \\
\hline
\end{tabular}

approximated by

$$
n^{*} \approx\left[\frac{2+z_{\beta}}{\left|\omega_{0}\right|} \sigma_{N} \sqrt{\frac{1+\phi}{1-\phi}}\right]^{2 / 3},
$$

where $\omega_{0}$ is the rate of change per year, $\sigma_{N}$ is the standard deviation of deseasonalized anomalies, and $\phi$ is the autocorrelation coefficient with lag 1 . Using $z_{\beta}=0$ or 1.3 provides the number of years to detect a trend of magnitude $\omega_{0}$ at the $95 \%$ confidence level with a probability of $50 \%$ and $90 \%$, respectively (Weatherhead et al. 1998; Loeb et al. 2007b). Based on CERES-EBAF data, the standard deviation and autocorrelation coefficient of monthly deseasonalized TOA shortwave irradiances are $0.545 \mathrm{~W} \mathrm{~m}^{-2}$ and 0.114 , respectively. Based on these values and Eq. (25), the number of years to detect a trend of reflected shortwave irradiance with a perfect instrument with a probability of $90 \%$ is listed in Table 3 .

\section{Summary and conclusions}

This paper describes TOA and surface irradiance data products produced by the CERES project for climate research. Algorithms used for the process are greatly improved from those used in the ERBE project. The CERES project integrates MODIS and geostationary satellite observations, snow cover and sea ice extent derived from microwave instruments, and thermodynamic variables from reanalysis to improve TOA and surface irradiance estimates. It also uses an aerosol transport model that assimilates MODIS-derived aerosol optical thickness. In addition, it uses ocean temperature measurements to constrain the global mean net TOA irradiance for the Level-3B data product. Furthermore, CALIPSO and CloudSat and AIRS observations are used to correct bias errors in the cloud, temperature, and humidity profiles. The CERES project provides global and regional mean radiation budgets at various temporal scales.

The length of observations currently available in CERES data products is too short to detect climate feedback and to evaluate feedback processes in climate models. Because the system that generates noise is the same system that responds to the radiative forcing, however, the variability of TOA shortwave and longwave irradiances contains the information of the response to the radiative forcing (the signal may not be easy to extract). The atmospheric response to ENSO or TOA irradiance variability over a shorter time scale therefore provides a useful evaluation for climate models. As the observation period extends, the radiation budget change might emerge, which can then be used directly to constrain climate models. Earth radation budget observations are therefore indispensable especially when the Earth is changing due to radiative forcing.

\section{References}

Abbot, C. G., and F. E. Fowle, 1908a: Determination of the intensity of the solar radiation outside the Earth's atmosphere, otherwise termed "the Solar Constant Radiation". Annals of the Astrophysical Observatory of the Smithonian Institute. Vol. 2, Part 1, Smithonian Institute, Washington, D.C., USA, 11-124.

Abbot, C. G., and F. E. Fowle, 1908b: Radiatin and terrestrial temperature. Annals of the Astrophysical Observatory of the Smithonian Institute. Vol. 2, Part 2, Smithonian Institute, Washington, D.C., USA, 125201.

Ackerman, T. P., and G. M. Stokes, 2003: The atmospheric radiation measurement program. Phy. Today, 56, 38-44.

Allan, R. P., and M. A. Ringer, 2003: Inconsistencies between satellite estimates of longwave cloud forcing and dynamical fields from reanalyses. Geophys. Res. Lett., 30, 1491, doi:10.1029/ 2003 GL017019.

Allan, R. P., A. Slingo, and M. A. Ringer, 2002: Influence of dynamics on the changes in tropical cloud radiative forcing during the $1998 \mathrm{El}$ Niño. J. Climate, 15, 1979-1986.

Augustine, J. A., J. J. DeLuisi, and C. N. Long, 2000: SURFRAD - A national surface radiation budget network for atmospheric research. Bull. Amer. Meteor. Soc., 81, 2341-2358.

Barkstrom, B. R., 1984: The Earth Radiation Budget Experiment (ERBE). Bull. Amer. Meteor. Soc., 65, 1170-1185.

Cairns, B., 1995: Diurnal variation of cloud from ISCCP. Atmos. Res., 37, 133-146. 
Cess, R. D., and G. L. Potter, 1987: Exploratory studies of cloud radiative forcing with a general circulation model. Tellus A, 39, 460-473.

Cess, R. D., G. L. Potter, W. L. Gates, J.-J. Morcrette, and L. Corsetti, 1992: Comparison of general circulation models to Earth Radiation Budget Experiment data: Comparison of clear-sky fluxes. J. Geophys. Res., 97, 20421-20426.

Cess, R. D., M. Zhang, P. H. Wang, and B. A. Wielicki, 2001: Cloud structure anomalies over the tropical Pacific during the 1997/98 El Niño. Geophy. Res. Lett., 28, 4547-4550.

Cheng, A., and K.-M. Xu, 2011: Improved low-cloud simulation from a multiscale modeling framework with a third-order turbulence closure in its cloud-resolving model component. J. Geophys. Res., 116, D14101, doi:10.1029/2010JD015362.

Colbo, K., and R. A. Weller, 2009: Accuracy of the IMET sensor package in the subtropics. J. Atmos. Oceanic Technol., 26, 1867-1890.

Cole, J., H. W. Barker, N. G. Loeb, and K. V. Salzen, 2011: Assessing simulated clouds and radiative fluxes using properties of clouds whose tops are exposed to space. J. Climate, 24, 2715-2727.

Collins, W. D., P. J. Rasch, B. E. Eaton, B. V. Khattatov, J.-F. Lamarque, and C. S. Zender, 2001: Simulating aerosols using a chemical transport model with assimilation of satellite aerosol retrievals: Methodology for INDOEX. J. Geophys. Res., 106, 73137336.

Doelling, D. R., N Loeb, D. F. Keyes, M. L. Nordeen, D. Morstad, B. A. Wielicki, D. F. Young, and M. Sun, 2013: Geostationary enhanced temporal interpolation for CERES flux products. J. Atmos. Oceanic Technol., 30, 1072-1090.

Dessler, A. E., 2010: A determination of the cloud feedback from climate variations over the past decade. Science, 330, 1523-1527.

Dessler, A. E., 2013: Observations of climate feedbacks over 2000-10 and comparisons to climate models. $J$. Climate, 26, 333-342.

Eitzen, Z. A., K. M. Xu, and T. Wong, 2011: An estimate of low-cloud feedbacks from variations of cloud radiative and physical properties with sea surface temperature on interannual time scales. J. Climate, 24, 1106-1121.

Flato, G., J. Marotzke, B. Abiodun, P. Braconnot, S. C. Chou, W. Collins, P. Cox, F. Driouech, S. Emori, V. Eyring, C. Forest, P. Gleckler, E. Guilyardi, C. Jakob, V. Kattsov, C. Reason, and M. Rummukainen, 2013: Evaluation of Climate Models. Climate Change 2013: The Physical Science Basis. Contribution of Working Group I to the Fifth Assessment Report of the Intergovernmental Panel on Climate Change, Stocker, T. F., D. Qin, G.-K. Plattner, M. Tignor, S. K. Allen, J. Boschung, A. Nauels, Y. Xia, V. Bex, and
P. M. Midgley (eds.), Cambridge University Press, Cambridge, United Kingdom and New York, USA.

Green, R. N., and L. M. Avis, 1996: Validation of ERBS scanner radiances. J. Atmos. Oceanic Technol., 13, 851-862.

Gregory, J. M., 2000: Vertical heat transports in the ocean and their effect on time-dependent climate change. Climate Dyn., 16, 501-515.

Haeffelin, M., R. Kandel, and C. Stubenrauch, 1999: Improved diurnal interpolation of reflected broadband shortwave observations using ISCCP data. $J$. Atmos. Oceanic Technol., 16, 38-54.

Hansen, J., G. Russell, A. Lacis, I. Fung, and D. Rind, 1985: Climate response time: Dependence on climate sensitivity and ocean mixing. Science, 229, 857-859.

Harrison, E., F. P. Minnis, B. R. Barkstrom, V. Ramanathan, R. D. Cess, and G. G. Gibson, 1990: Seasonal variation of cloud radiative forcing derived from the Earth Radiation Budget Experiment. J. Geophys. Res., 95, 18687-18730.

Hartmann, D. L., V. Ramanathan, A. Berroir, and G. E. Hunt, 1986: Earth radiation budget data and climate research. Rev. Geophys., 24, 439-468.

Hartmann, D., K. J. Kowalewsky, and M. Michelsen, 1991: Diurnal variation of outgoing longwave radiation and albedo from ERBE scanner data. J. Climate, 4, 598-617.

Held, I. M., M. Winton, K. Takahashi, T. Delworth, F. Zeng, and G. K. Vallis, 2010: Probing the fast and slow components of global warming by returning abruptly to preindustrial forcing. J. Climate, 23, 2418-2427.

House, F. B., A. Gruber, G. E. Hunt, and A. T. Mecherikunnel, 1986: History of satellite mission and measurements of the Earth radiation budget (19571984). Rev. Geophys., 24, 357-377.

Huffman, G. J., R. F. Adler, P. Arkin, A. Chang, R. Ferraro, A. Gruber, J. Janowiak, A. McNab, B. Rudolf, and U. Schneider, 1997: The Global Precipitation Climatology Project (GPCP) combined precipitation dataset. Bull. Amer. Meteor. Soc., 78, 5-20.

Hunt, G. E., R. Kandel, and A. T. Mecherikunnel, 1986: A history of presatellite investigation of the Earth's radiation budget. Rev. Geophys., 24, 351-356.

Jin, Z., T. P. Charlock, W. L. Smith, Jr., and K. Rutledge, 2004: A parameterization ocean surface albedo. Geophys. Res. Lett., 31, L22301, doi:10.1029/2004GL021180.

Kandel, R., and M. Viollier, 2005: Planetary radiation budget. Space Sci. Rev., 120, 1-26.

Kandel, R., and M. Viollier, 2010: Observation of the Earth's radiation budget from space. Comptes Rendus Geosci., 342, 286-300.

Kato, S., 2009: Interannual variability of global radiation budget. J. Climate, 22, 4893-4907.

Kato, S., and N. G. Loeb, 2003: Twilight irradiance 
reflected by the Earth estimated from Clouds and the Earth's Radiant Energy System (CERES) measurements. J. Climate, 16, 2646-2650.

Kato, S., and N. G. Loeb, 2005: Top-of-atmosphere shortwave broadband observed radiance and estimated irradiance over polar regions from Clouds and the Earth's Radiant Energy System (CERES) instruments on Terra. J. Geophys. Res., 110, D07202, doi:10.1029/2004JD005308.

Kato, S., F. G. Rose, S. Sun-Mack, W. F. Miller, Y. Chen, D. A. Rutan, G. L. Stephens, N. G. Loeb, P. Minnis, B. A. Wielicki, D. M. Winker, T. P. Charlock, P. W. Stackhouse, K.-M. Xu, and W. Collins, 2011: Improvements of top-of-atmosphere and surface irradiance computations with CALIPSO, CloudSat, and MODIS derived cloud and aerosol properties. J. Geophys. Res., 116, D19209, doi:10.1029/2011JD16050.

Kato, S., N. G. Loeb, D. A. Rutan, F. G. Rose, S. Sun-Mack, W. F. Miller, and Y. Chen, 2012: Uncertainty estimate of surface irradiances computed with MODIS-, CALIPSO-, and CloudSat-derived cloud and aerosol properties. Surv. Geophys., 33, 395-412.

Kato, S., N. G. Loeb, F. G. Rose, D. R. Doelling, D. A. Rutan, T. E. Caldwell, L. Yu, and R. A. Weller, 2013: Surface irradiances consistent with CERES-derived top-of-atmosphere shortwave and longwave irradiances. J. Climate, 26, 2719-2740.

Klein, S. A., B. J. Soden, and N.-C. Lau, 1999: Remote sea surface temperature variation during ENSO: Evidence for a tropical atmospheric bridge. $J$. Climate, 12, 917-932.

L'Ecuyer, T., H. K. Beaudoing, M. Rodell, W. Olson, B. Lin, S. Kato, C. A. Clayson, E. Wood, J. Sheffield, R. Adler, G. Huffman, M. Bosilovich, G. Gu, F. Robertson, P. R. Houser, D. Chambers, J. S. Famiglietti, E. Fetzer, W. T. Liu, X. Gao, C. A. Schlosser, E. Clark, D. P. Letternmaier, and K. Hilburn, 2015: The observed state of the energy budget in the early 21 st century. J. Climate, 28, 8319-8346.

Leroy, S. S., J. G. Anderson, and G. Ohring, 2008: Climate signal detection times and constraints on climate benchmark accuracy requirements. J. Climate, 21, 841-846.

Loeb, N. G., K. J. Priestly, D. P. Kratz, E. B. Geier, R. N. Green, and B. A. Wielicki, 2001: Determination of unfiltered radiances from the Clouds and the Earth's Radiant Energy System instrument. J. Appl. Meter., 40, 822-825.

Loeb, N. G., S. Kato, and B. A. Wielicki, 2002: Defining top-of-atmosphere flux reference level for earth radiation budget studies. J. Climate, 15, 3301-3309.

Loeb, N. G., N. Manalo-Smith, S. Kato, W. F. Miller, S. K. Gupta, P. Minnis, and B. A. Wielicki, 2003: Angular distribution models for top-of-atmosphere radiatie flux estimation from the Clouds and the Earth's
Radiant Energy System instrument on the Tropical Rainfall Measureing Mission satellite. Part I: Methodology. J. Appl. Meteor, 42, 240-265.

Loeb, N. G., S. Kato, K. Loukachine, and M. N. Natividad, 2005: Angular distribution models for top-of-atmosphere radiative flux estimation from the Clouds and the Earth's Radiant Energy System instrument on the Terra satellite. Part I: Methodology. J. Appl. Meteor., 22, 338-351.

Loeb, N. G., S. Kato, K. Loukachine, M. N. Natividad, and D. R. Doelling, 2007a: Angular distribution models for top-of-atmosphere radiative flux estimation from the Clouds and the Earth's Radiant Energy System instrument on the Terra satellite. Part II: Validation. J. Appl. Meteor., 24, 564-584.

Loeb, N. G., B. A. Wielicki, W. Su, K. Loukachine, W. Sun, T. Wong, K. J. Priestley, G. Matthews, W. F. Miller, and R. Davies, 2007b: Multi-instrument comparison of top-of-atmosphere reflected solar radiation. $J$. Climate, 20, 575-591.

Loeb, N. G., B. A. Wielicki, F. G. Rose, and D. R. Doelling, 2007c: Variability in global top-of-atmosphere shortwave radiation between 2000 and 2005. Geophys. Res. Lett., 34, L03704, doi:10.1029/2006GL028196.

Loeb, N. G., B. A. Wielicki, D. R. Doelling, G. L. Smith, D. F. Keyes, S. Kato, N. Manalo-Smith, and T. Wong, 2009a: Toward optimal closure of the earth's top-of-atmosphere radiation budget. J. Climate, 22, $748-766$.

Loeb, N. G., B. A. Wielicki, T. Wong, and P. A. Parker, 2009b; Impact of data gaps on satellite broadband radiation records. J. Geophys. Res., 114, D11109, doi:10.1029/2008JD011183.

Loeb, N. G., J. M. Lyman, G. C. Johnson, R. P. Allan, D. R. Doelling, T. Wong, B. J. Soden, and G. L. Stephens, 2012: Observed changes in top-of-the-atmosphere radiation and upperocean heating consistent within uncertainty. Nat. Geosci., 5, 110-113.

McPhaden, M. J., 2002: TAO/TRITON tracks Pacific Ocean warming in early 2002. CLIVAR Exchanges, 24, 7-9.

McPhaden, M. J., G. Meyers, K. Ando, Y. Masumoto, V. S. N. Murty, M. Ravichandran, F. Syamsudin, J. Vialard, L. Yu, and W. Yu, 2009: RAMA: The research moored array for African-Asian-Australian monsoon analysis and prediction. Bull. Amer. Meteor. Soc., 90, 459-480.

Minnis, P., and E. F. Harrison, 1984: Diurnal variability of regional cloud and clear-sky radiative parameters derived from GOES data. Part III: November 1978 radiative parameters. J. Climate Appl. Meteor., 23, 1032-1051.

Minnis, P., S.-M. Szedung, D. F. Young, P. W. Heck, D. P. Garber, C. Yan, D. A. Spangenberg, R. F. Arduini, Q. Z. Trepte, W. L. Smith, J. K. Ayers, S. C. Gibson, W. 
F. Miller, G. Hong, V. Chakrapani, V. Takano, K.-N. Liou, X. Yu, and P. Yang, 2011: CERES Edition-2 cloud property retrievals using TRMM VIRS and Terra and Aqua MODIS data, Part I: Algorithms. IEEE Trans. Geosci. Remote Sens., 49, 4374-4400.

Ohmura, A., 2014: The development and the present status of energy balance climatology. J. Meteor. Soc. Japan, 92, 245-285.

Ohmura, A., E. Dutton, B. Forgan, C. Frohlich, H. Gilgen, H. Hegne, A. Heimo, G. Konig-Langlo, B. McArthur, G. Muller, R. Philipona, C. Whitlock, K. Dehne, and M. Wild, 1998: Baseline Surface Radiation Network (BSRN/WCRP): New precision radiometry for climate change research. Bull. Amer. Meteor. Soc., 79, 2115-2136.

Painemal, D., K.-M. Xu, A. Cheng, P. Minnis, and R. Palikonda, 2014: Mean structure and diurnal cycle of Southeast Atlantic boundary layer clouds: Insights from satellite observations and multiscale modeling framework simulations. J. Climate, 28, 324-341.

Phojanamongkolkij, N., S. Kato, B. A. Wielicki, P. C. Taylor, and M. G. Mlynczak, 2014: A comparison of climate signal trend detection uncertainty analysis methods. J. Climate, 3363-3376.

Potter, G. L., R. D. Cess, P. Minnis, E. F. Harrison, and V. Ramanathan, 1988: Diurnal variability of the planetary albdo: an appraisal with satellite measurements and general circulation models. J. Climate, 1, 233-239.

Qu, X., A. Hall, S. A. Klein, and P. M. Caldwell, 2014: On the spread of changes in marine low cloud cover in climate model simulations of 21 st century. Climate Dyn., 42, 2603-2626.

Ramanathan, V., R. D. Cess, E. F. Harrison, P. Minnis, B. R. Barkstrom, E. Ahmad, and D. Hartmann, 1989: Cloud-radiative forcing and climate: Results from the Earth Radiation Budget Experiment. Science, 243, 57-63.

Randel, D. L., and T. H. Vander Haar, 1990: On the interannual variation of the earth radiation budget. $J$. Climate, 3, 1168-1173.

Raschke, E., A. Ohmura, W. R. Rossow, B. E. Carlson, Y.-C. Zhang, C. Stubenrauch, M. Kottek, and M. Wild, 2005: Cloud effect on the radiation budget based on ISCCP data (1991 to 1995). Int. J. Climatol., 25, 1103-1125.

Ringer, M. A., 1997: Interannual variability of the earth's radiation budget: Some regional studies. Int. J. Climatol., 17, 929-951.

Ringer, M. A., and K. P. Shine, 1997: Sensitivity of the Earth's radiation budget to interannual variations in cloud amount. Climate Dyn., 13, 213-222.

Rose, F. G., D. A. Rutan, T. Charlock, G. L. Smith, and S. Kato, 2013: An algorithm for the constraining of radiative transfer calculations to CERES-observed broadband top-of-atmosphere irradiance. J. Atmos.
Oceanic Technol., 30, 1091-1106.

Rossow, W. B., and R. A. Schiffer, 1991: ISCCP cloud data products. Bull. Amer. Meteor. Soc., 72, 1-20.

Rossow, W. B., and Y.-C. Zhang, 1995: Calculation of surface and top of atmosphere radiative fluxes from physical quantities based on ISCCP data set 2. Validation and first results. J. Geophys. Res., 100, 11671197.

Rossow, W. B., and R. A. Schiffer, 1999: Advances in understanding clouds from ISCCP. Bull. Amer. Meteor. Soc., 80, 2261-2287.

Rozendaal, M. A., C. B. Leovy, and S. A. Klein, 1995: An observational study of diurnal cycle variations of marine stratiform cloud. J. Climate, 8, 1795-1809.

Rutan, D., F. Rose, M. Roman, N. Manalo-Smith, C. Schaaf, and T. Charlock, 2009: Development and assessment of broadband surface albedo from Clouds and the Earth's Radiant Energy System clouds and radiation swath data product. J. Geophys. Res., 114, D08125, doi:10.1029/2008JD010669.

Rutan, D. A., S. Kato, D. R. Doelling, F. G. Rose, L. T. Nguyen, T. E. Caldwell, and N. G. Loeb, 2014: CERES synoptic product: Methodology and validation of surface radiant flux. J. Atmos. Oceanic. Technol., 32, 1121-1143.

Servain, J., A. J. Busalacchi, M. J. McPhaden, A. D. Moura, G. Reverdin, M. Vianna, and S. E. Zebiak, 1998: A Pilot Research Moored Array in the Tropical Atlantic (PIRATA). Bull. Amer. Meteor. Soc., 79, 2019-2031.

Sherwood, S. C., S. Bony, and J.-L. Dufresne, 2014: Spread in model climate sensitivity traced to atmospheric convective mixing. Nature, 505, 37-42.

Smith, E. A., and M. R. Smith, 1987: Interannual variability of the tropical radiation balance and the role of extended cloud system. J. Atmos. Sci., 44, 32103234.

Smith, G. L., D. Rutan, T. P. Charlock, and T. D. Bess, 1990: Annual and interannual variations of absorbed solar radiation based on a 10 -year data set. $J$. Geophys. Res. 95, 16639-16652.

Soden, B. J., I. M. Held, R. Colman, K. M. Shell, J. T. Kiehl, and C. A. Shield, 2008: Quantifying climate feedbacks using radiative kernels. J. Climate, 21, 3504-3520.

Sohn, B. J., and R. Bennartz, 2008: Contribution of water vapor to observational estimates in longwave cloud radiative forcing. J. Geophys. Res., 113, doi: 10.1029/2008JD010053.

Sohn, B. J., T. Nakajima, M. Satoh, and H.-S. Jang, 2010: Impact of different difinitions of clear-sky flux on the determination of longwave cloud radiative forsing: NICAM simulation results. Atmos. Chem. Phys., 10, 11641-11646.

Stephens, G. L., and T. J. Greenwald, 1991a: The Earth's radiation budget and its relation to atmospheric 
hydrology 1. Observations of the clear sky greenhouse effect. J. Geophys. Res., 96, 15311-15324.

Stephens, G. L., and T. J. Greenwald, 1991b: The Earth's radiation budget and its relation to atmospheric hydrology 1. Observations of cloud effect. $J$. Geophys. Res. 96, 15325-15340.

Stephens, G. L., and T. D. Ellis, 2008: Controls of global mean precipitation increases in global warming GCM experiments. J. Climate, 6141-6155.

Stephens, G. L., J. Li, M. Wild, C. A. Clayson, N. Loeb, S. Kato, T. L'Ecuyer, P. W. Stackhouse, M. Lebsock, and T. Andrews, 2012: An update on Earth's energy balance in light of the latest global observations. Nat. Geosci., 5, 691-696.

Stevens, B., and S. E. Schwartz, 2012: Observing and modeling Earth's energy flows. Surv. Geophys. 33, 779-816.

Su, W., A. Bodas-Salcedo, K.-M. Xu, and T. Charlock, 2010: Evaluation of the radiative flux and cloud effect profiles in a climate model with the Clouds and the Earth's Radiant Energy System (CERES) data. J. Geophys. Res., 115, D01105, doi:10.1029/2009JD012490.

Su, W., J. Corbett, Z. Eitzen, and L. Liang, 2015: Next-generation angular distribution models for top-of-atmosphere radiative flux calculation from the CERES instruments: Methodology. Atmos. Meas. Technol. Discuss., 7, 8817-8880.

Taylor, B. N., and C. E. Kuyatt, 1994: Guidelines for evaluating and expressing the uncertainty of NIST measurement results. NIST technical note 1994 edition.

Taylor, P. C., and N. G. Loeb, 2013: Impact of sun-synchronous diurnal sampling on tropical TOA flux interannual variability and trend. J. Climate, 26, 2184-2191.

Trenberth, K. E., J. T. Fasullo, and J. Kiehl, 2009: Earth's global energy budget. Bull. Amer. Meteor. Soc., 90, 311-323.

Tsushima, Y., and S. Manabe, 2013: Assessment of radiative feedback in climate models using satellite observations of annual flux variation. Proceedings of the National Academy of Sciences, 110, 7568-7573.

Weatherhead, E. C., G. C. Reinsel, G. C. Tiao, X.-L. Meng, D. Choi, W.-K. Cheang, T. L. Keller, J. DeLuisi, D. J. Wuebbles, J. B. Kerr, A. J. Miller, S. J Oltmans, and J. E. Frederick, 1998: Factors affecting the detection of trends: Statistical considerations and applications to environmental data. J. Geophys. Res., 103, 1714917161.

Wielicki, B. A., and R. N. Green, 1989: Cloud identification for ERBE radiative flux retrieval. J. Appl. Meteor, 28, 1133-1146.

Wielicki, B. A., R. D. Cess, M. D. King, D. A. Randall, and E. F. Harrison, 1995: Mission to planet earth: Role of clouds and radiation in climate. Bull. Amer. Meteor.
Soc., 71, 2125-2153.

Wielicki, B. A., B. R. Barkstrom, E. F. Harrison, R. B. Lee III, G. L. Smith, and J. E. Cooper, 1996: Clouds and the Earth's Radiant Energy System (CERES): An earth observing system. Bull. Amer. Meteor. Soc., 72, 853-868.

Wielicki, B. A., B. R. Barkstrom, B. A. Baum, T. P. Charlock, R. N. Green, D. P. Kratz, R. B. Lee, P. Minnis, G. L. Smith, T. Wong, D. F. Young, R. D. Cess, J. A. Coakley, D. A. H. Crommelynck, L. Donner, R. Kandel, M. D. King, A. J. Miller, V. Ramanathan, D. A. Randall, L. L. Stowe, and R. M.Welch, 1998: Clouds and the Earth's Radiant Energy System (CERES): Algorithm overview. IEEE Trans. Geosci. Remote Sens., 36, 1127-1141.

Wielicki, B. A., T. Wong, R. P. Allan, A. Slingo, J. T. Kiehl, B. J. Soden, C. T. Gordon, A. J. Miller, S.-K. Yang, D. A. Randall, F. Robertson, J. Susskind, and H. Jacobowitz, 2002: Evidence for large decadal variability in the tropical mean radiative energy budget. Science, 295, 841-844.

Wielicki, B. A., D. F. Young, M. G. Mlynczak, K. J. Thome, S. Leroy, J. Corliss, J. G. Anderson, C. O. Ao, R. Bantges, F. Best, K. Bowman, H. Brindley, J. J. Butler, W. Collins, J. A. Dykema, D. R. Doelling, D. R. Feldman, N. Fox, X. Huang, R. Holz, Y. Huang, Z. Jin, D. Jennings, D. G. Johnson, K. Jucks, S. Kato, D. B. Kirk-Davidoff, R. Knuteson, G. Kopp, D. P. Kratz, X. Liu, C. Lukashin, A. J. Mannucci, N. Phojanamongkolkij, P. Pilewskie, V. Ramaswamy, H. Revercomb, J. Rice, Y. Roberts, C. M. Roithmayr, F. Rose, S. Sandford, E. L. Shirley, W. L. Smith, Sr., B. Soden, P. W. Speth, W. Sun, P. C. Taylor, D. Tobin, and X. Xiong, 2013: Achieving climate change absolute accuracy in orbit. Bull. Amer. Meteor. Soc., 94, 1519-1539.

Wilber, A. C., D. P. Kratz, and S. K. Gupta, 1999: Surface emissivity maps for use in satellite retrievals of longwave radiation. NASA Tech. Meno., TP-1999209362, 30 pp.

Wong, T., B. A. Wielicki, R. B. Lee III, G. L. Smith, K. A. Bush, and J. K. Willis, 2006: Reexamination of the observed decadal variability of the Earth radiation budget using altitude-corrected ERBE/ERBS nonscanner WFOV data. J. Climate, 19, 4028-4040.

$\mathrm{Xu}, \mathrm{K} .-\mathrm{M}$., and A. Cheng, 2013a: Evaluating low cloud simulation from an upgraded multiscale modeling framework. Part I: Sensitivity to spatial resolution and climatology. J. Climate, 26, 5717-5740.

$\mathrm{Xu}, \mathrm{K} .-\mathrm{M}$., and A. Cheng, 2013b: Evaluating low cloud simulation from an upgraded multiscale modeling framework. Part II: Seasonal variations over the eastern Pacific. J. Climate, 26, 5741-5760.

Young, D. F., P. Minnis, D. R. Doelling, G. G. Gibson, and T. Wong, 1998: Temporal interpolation methods for the Clouds and the Earth's Radiant Energy System 
(CERES) experiment. J. Appl. Meteor., 37, 572-590.

Zhang, Y.-C., and W. B. Rossow, 1995: Calculation of surface and top of atmosphere radiative fluxes from physical quantities based on ISCCP data set 1 . Method and sensitivity to input data uncertainties. $J$. Geophys. Res., 100, 1149-1165.

Zhang, Y.-C., W. B. Rossow, A. A. Lacis, V. Oinas, and
M. I. Mishchenko, 2004: Calculation of radiative fluxes from the surface to top of atmosphere based on ISCCP and other global data sets: Refinements of the rediative transfer model and the input data. J. Geophys. Res., 109, D19105, dio:10.1029/2003JD004457. 